\title{
Looking at light through a pinhole
}

Nancy Magnani, Karen Neville, Matthew Donnelly

Nancy Magnani, Karen Neville, Matthew Donnelly, "Looking at light through a pinhole," Proc. SPIE 8481, Optics Education and Outreach II, 84810V (15 October 2012); doi: 10.1117/12.929250

SPIE Event: SPIE Optical Engineering + Applications, 2012, San Diego, California, United States 


\title{
Looking at light through a pinhole
}

\author{
Nancy Magnani*a, Karen Neville ${ }^{\mathrm{a}}$, Mathew Donnelly ${ }^{\mathrm{b}}$ \\ ${ }^{a}$ EASTCONN, 376 Hartford Turnpike, Hampton, CT 06076; ${ }^{\mathrm{b}}$ Three Rivers Community College, 574 \\ New London Turnpike, Norwich, CT 06360
}

\begin{abstract}
By learning about the principles of optics, Connecticut high school students will be able to produce high quality photographs using pinhole cameras. In this project, a class of photography students has partnered with a class of physics students to learn about optics, build pinhole cameras, use commercially available pinhole cameras and produce quality photographs. In this paper, the results of this student partnership under the guidance of the Laser and Fiber Optic Technology program at Three Rivers Community College and EASTCONN, a regional education service center will be explained.
\end{abstract}

Keywords: pinhole photography, pinhole camera, Laser Camp, pinhole viewers, oatmeal container cameras, student outreach, OSA and SPIE student chapters

\section{INTRODUCTION}

Photography presents a unique opportunity to learn about optics. Through the use of pinhole photography, students can learn about how light travels, how images are created, what exposure is required for a good image, and (in the case of film photography) the chemistry of photo development.

For the past several years, the Minds in Motion Interdistrict grant program at EASTCONN and the Laser and Fiber Optic Technology (LFOT) program at Three Rivers Community College (TRCC) have partnered to present Laser Camp to high school students in northeastern Connecticut. ${ }^{1}$ The goal of Minds in Motion is to promote positive relationships among students from different school districts and increase students' academic achievement through hands-on scientific exploration. Laser Camp is a collection of hands-on workshops that instruct students in optical science and applications. The pinhole camera workshop has always been one of the most popular workshops but the resulting photographs have not always been successful.

During the 55 minute Laser Camp pinhole camera workshop, students make pinhole cameras from oatmeal boxes and pinholes drilled in thin aluminum, load the film, take a photo and develop it in the TRCC darkroom. Because of time limitations, students can only take and develop one photograph and if there is a light leak or the exposure is not correct the students are disappointed. As a result, this year we have decided to make pinhole photography a full day learning opportunity instead of a 50-minute workshop. While the Laser Camp activities are geared toward science and technology students, for Pinhole Photography Day we added photography students. The two groups were from a rural high school and a high school located in a small city. Once again, the workshop was held at Three Rivers Community College with the assistance of members of the student chapters of OSA and SPIE. The goal was to improve the quality of the photographs by providing more background on the science, though as explained in this paper, not every photo was successful.

\section{STRUCTURE OF PINHOLE PHOTOGRAPHY DAY}

Because our Pinhole Photography Day would include two diverse groups of students from two different high schools, a short history of pinhole photography and some scientific background was provided to the teachers to present to the students so that they would be more focused on the day's activities.

*nmagnani@eastconn.org; phone 1860 455-1536; fax 1860 455-1005; eastconn.org

Optics Education and Outreach II, edited by G. Groot Gregory, Proc. of SPIE Vol. 8481

84810V · (C) 2012 SPIE · CCC code: 0277-786/12/\$18 · doi: 10.1117/12.929250 
Also, presenting this information in the individual classroom and reviewing the agenda with the students before the actual event, allowed more time to be available for taking and developing photos. Both groups of students were familiar with taking photos with digital cameras and cameras on their phones, but pinhole photography was a new experience. Students were told that for this type of photography, they would use a camera with no lens.

\subsection{Pinhole photography day agenda}

The day began with students meeting in a large TRCC classroom for an overview of the day's agenda and a collegestyle presentation by Professor Judy Donnelly of the TRCC LFOT program on the creation of images by a pinhole. This set the tone of the day and reinforced the message to the students that this was still a school day. The students were instructed that they would attend three workshops: making a pinhole camera from an oatmeal container; using a purchased pinhole camera with $35 \mathrm{~mm}$ black and white film and a lecture by Robert Calafiore, Assistant Dean and Professor of Photography at Hartford Art School of the University of Hartford, who specializes in pinhole photography.

\subsection{Pinhole viewer lesson}

In the lesson on pinhole viewers, Donnelly began by challenging students with the question, "Can you make a photograph with just an empty box with a pinhole on one side?" Using animated Power Point slides, she explained how each point on the object has a corresponding point on the pinhole image. (See Figure 1.) She also explained how pinhole images form under leafy branches and showed examples of pinhole images of the sun formed by a pergola covered with rose vines. (See Figure 2.) Finally, she gave recommendations for making good pinhole photos with a home-made pinhole camera:

- The pinhole should be round, with smooth edges

- Check the box carefully for light leaks

- You MUST put the box on something sturdy for the exposure- you can't hold it in your hands

- Try to get good contrast in your photo (like branches against the sky). People usually make poor subjects.
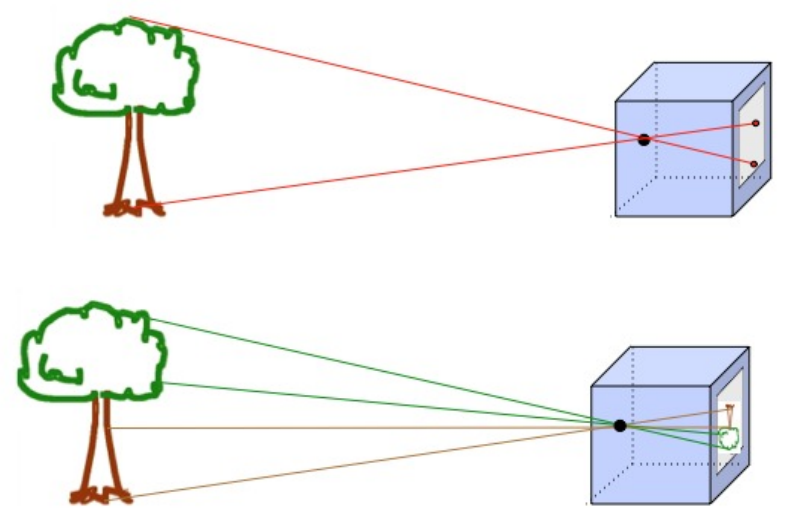

Figure 1 - Illustrating the formation of a pinhole image. Top: Tracing path of a laser beam from the top and bottom of the tree Bottom: Light from the object forms a corresponding point on the image. 

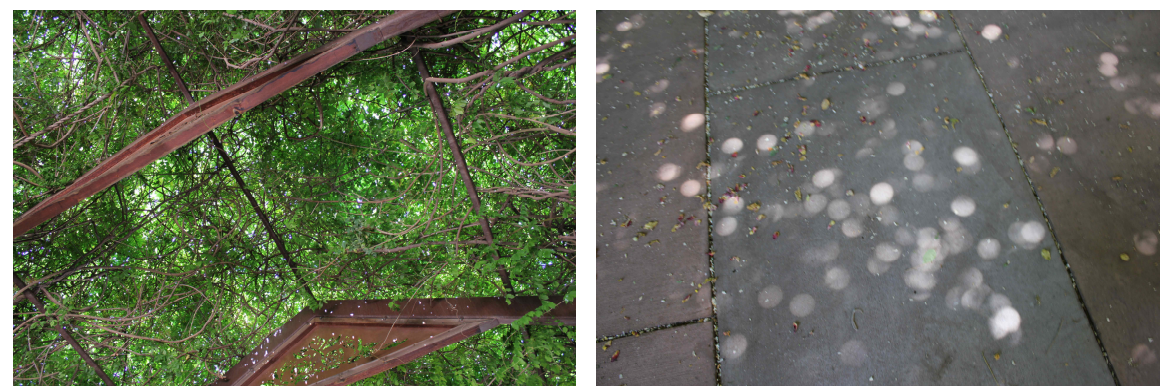

Figure 2 - The small openings between leaves on a pergola covered with thick rose vines creates pinhole images of the sun in a rose garden. Left: vine-covered pergola, Left: pinhole images of the sun form underneath. (J. Donnelly photo)

\section{PINHOLE PHOTOGRAPHY WORKSHOPS}

At the conclusion of Professor Donnelly's lesson, the students were separated into three small groups of students of 10 or 11 students. Each small group would attend all of the workshops. The workshops were each slightly over 60 minutes in length and are described in the following order: 1) Make your own camera, 2) Using a Purchased Pinhole Camera and 3) Professional Photography Workshop.

\section{WORKSHOP 1: MAKE YOUR OWN CAMERA}

\subsection{Oatmeal container pinhole cameras}

In the first workshop, the students made their cameras of oatmeal containers. The instructions were adapted from sources on the Internet. ${ }^{3,4}$ The oatmeal containers is pre-painted with black spray paint on the inside and heavy black cardboard inserts were placed in the container tops to prevent light leaking through the translucent plastic.

Students were first instructed to make a pinhole in a piece of aluminum cut from a soda can. The metal was placed on a small piece of corrugated cardboard and a hole was "drilled" using a sewing needle pushed into the eraser end of a pencil. Students were told to use the pencil like a drill and stop as soon as the metal was just pierced. Then, turn the metal over and drill from the other side, repeating until the hole was about as large as the diameter of the needle a few $\mathrm{mm}$ from the tip (refer to figure 3). Although drilling from side to side created a smoother hole, it occasionally resulted in a double hole in which case students needed to start with a fresh piece of aluminum.

After drilling the holes were lightly sanded on both sides with 600 grit wet or dry sandpaper. To check for size and shape of the hole, each student examined his/her pinhole using a USB microscope (ProScope HR, Bodelin Technologies) projected on the classroom screen (refer to figure 3). Pinhole diameters were measured with xScope for Mac OS (The Iconfactory). Because the ruler default is in pixels, students were told that the first task was to calibrate the measuring device, which was accomplished by determining the width of a piece of $125 \mu \mathrm{m}$ optical fiber in pixels. A simple calculation allowed the pinhole diameter to be determined. This exercise emphasized the need for calibrating instruments and the usefulness of ratios in mathematics. (It should be noted that students were also delighted to see various surfaces in the laboratory at 100x as well as the contrast between the instructor's dark and gray hairs.) 

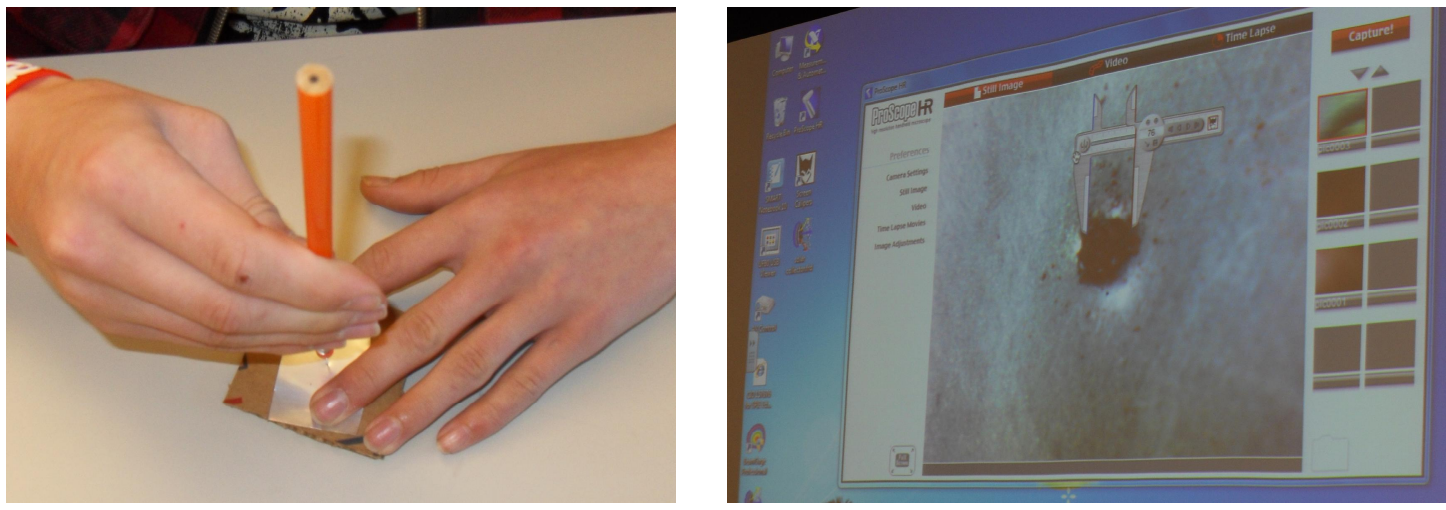

Figure 3 On the left, student making a pinhole. On the right, checking the size and shape of the pinhole.

A few pinholes needed no further work but if they were too small or uneven students were instructed to return to their seats and gently ream out the hole with the needle before checking it again. Once the pinhole was formed and the right size (which we calculated with the students to be just under $0.5 \mathrm{~mm}$ for the boxes we were using) it was fastened over a pre-cut hole in the center of one side of the box. ${ }^{5}$ In figure 4, students are making their cameras. A shutter was formed by covering the pinhole with a piece of electrical tape, folding the end over so that the adhesive was not in contact with the pinhole. Before leaving the classroom to load the film, the students were reminded that they needed to keep the shutter closed except for during exposure and that they needed to put the camera on a solid base for exposure. Finally, even though it is fun to take photos of friends, they usually do not come out as well as photos of inanimate objects.
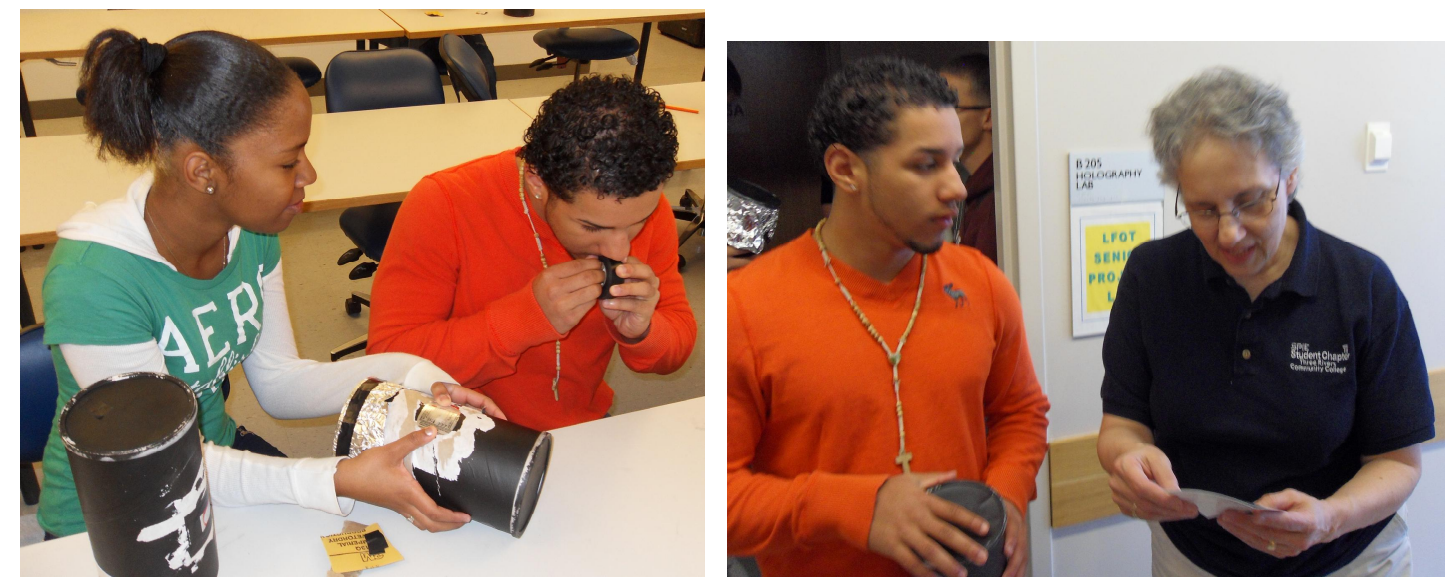

Figure 4 On the left, students making cameras. On the right, a student showing results to Professor Donnelly.

\subsection{Taking photos with the oatmeal container camera}

Film loading was done in one of the TRCC optics labs in near total darkness (a desk lamp with a red safe light was under one table). Students were shown the room before the lights were turned out so they were better able to navigate in the dark. The film was Ilford 5"x7" Multigrade IV Deluxe MGD.1 black and white variable contrast RC glossy paper; experience has shown that students are less likely to mount the film backwards in the oatmeal box when they can distinguish the glossy emulsion side. The film was affixed opposite the pinhole with doubled up piece of tape and the box was taped shut with black electrical tape. Because light leaks have been a problem in the past, the tops of the boxes were also encased in aluminum foil, down to the level of the pinhole. 
TRCC students led the high school students outside for the exposure, which was initially 5-6 seconds. After developing the film, students were given recommendations based on their results. Figure 4 shows a student sharing his photo with Professor Donnelly. Our experience with film paper is that an indoor exposure needs to be approximately 30 minutes, more time than we had for this workshop. One of the TRCC students did take a pinhole photo of a classroom where students were at work; her 30-minute exposure made with a foam board rectangular box camera is shown in Figure 5. Note that people do not appear in the photo because they were not motionless long enough to register on the film paper.
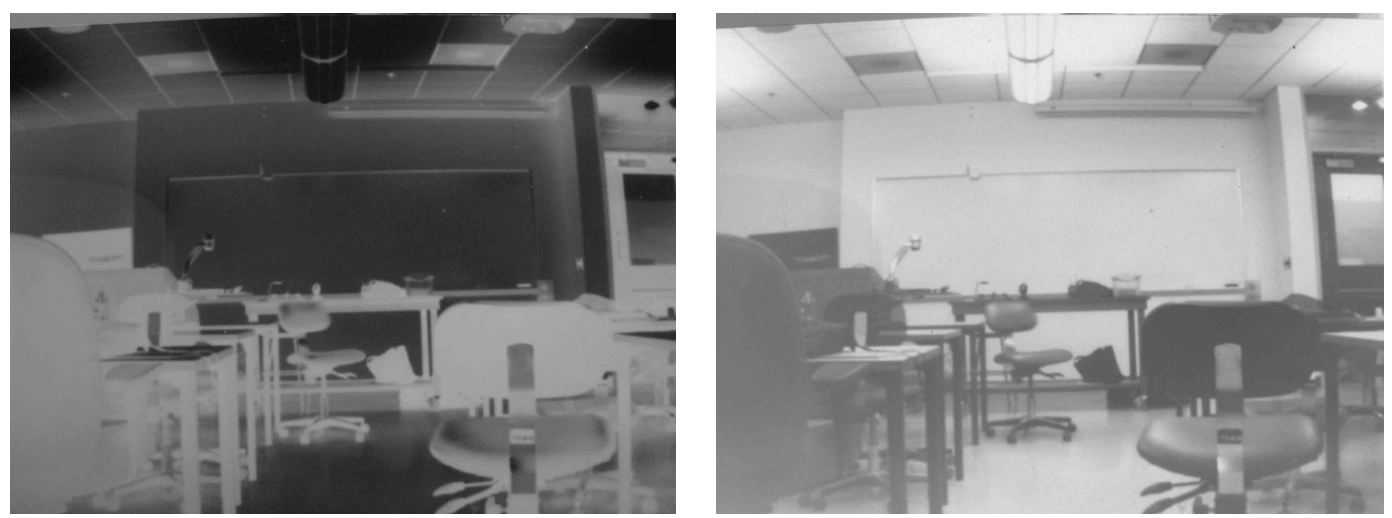

Figure 5: Pinhole camera photos of a classroom created with a rectangular box camera and a 30 minute exposure on black and white film paper. Left: original photo Right: scanned and inverted photo.

\subsection{Developing photos}

After exposing the film, students entered through the revolving darkroom door (a "cool" experience for many students who had never seen one before) and were instructed to open their cameras and carefully retrieve the film, noting which side was facing the pinhole. Film development was done by experienced TRCC students but final rinsing was done by the photographers. Developing chemistry used Ilford Multigrade Developer and the Ilford Rapid Fixer. Experience has shown that liquid chemicals are easier to handle than mixing powders. Because the spent fixer contains silver, it must be carefully funneled into hazardous waste bottles for later pick up.

As always, results were mixed although there were more successful photos than at Laser Camp. The most common problem is overexposure, presumably due to a light leak (assuming students accurately timed the exposure). Nonetheless, there were some very good photos taken, and the students were surprised with results particularly the odd curvature introduced by taping the film to a round container. Student comments included "These pinholes actually take great pictures!" and "Developing was awesome!" Example photos are shown in Figure 6.
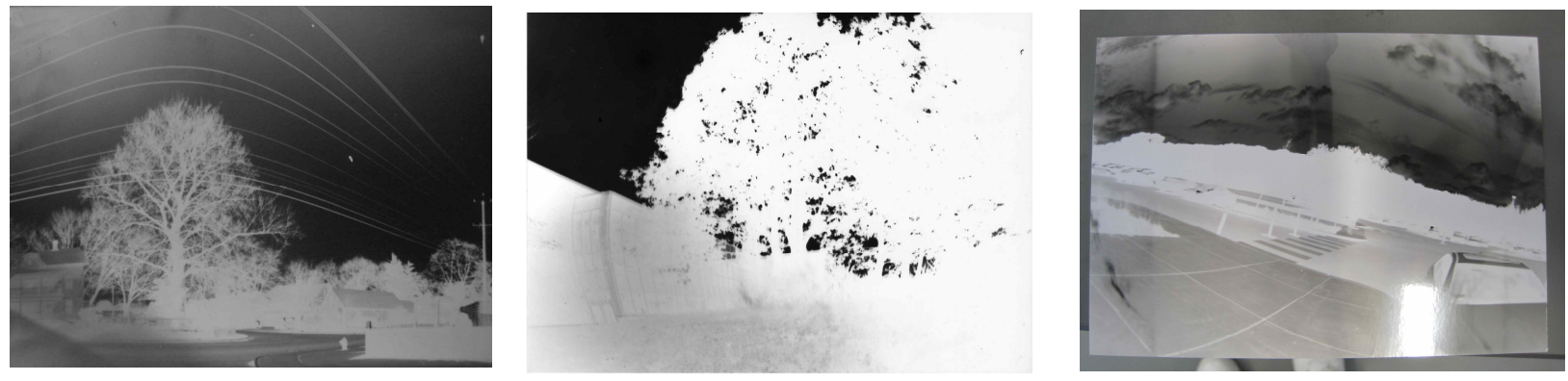

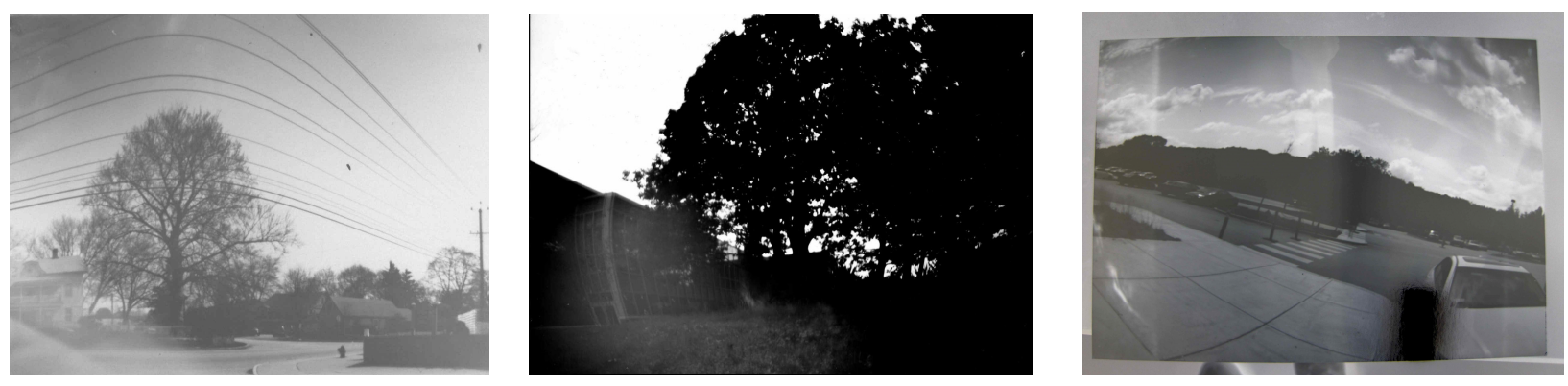

Figure 6 - Photos taken with oatmeal container pinhole cameras. The top row is the original photos, exposed on black and white film paper. The bottom row shows the same photos scanned and with digital color inversion applied.

\section{WORKSHOP 2: USING A PURCHASED PINHOLE CAMERA}

\subsection{Holga 135 PC pinhole camera}

For the second workshop, the students went "old school" and used a Holga 135 PC plastic pinhole camera (shown in figure 7), requiring $35 \mathrm{~mm}$ black and white film. Two cameras were purchased for approximately $\$ 45$. The lesson was explained to the students that they would have a roll of 24-exposure black and white film and after each photograph; they would have to advance the film to the next exposure. Exposure times would vary depending on the outdoor lighting conditions. Using the suggested exposure times included with the camera, the students would count the number of seconds to leave the shutter open. This varied from 1 second to as much as 7 seconds for bright sunny days or as much as 30 seconds on a cloudy day or in evening light. When the roll was complete, it would be taken to a local super store to be developed with the results available in several weeks' time.

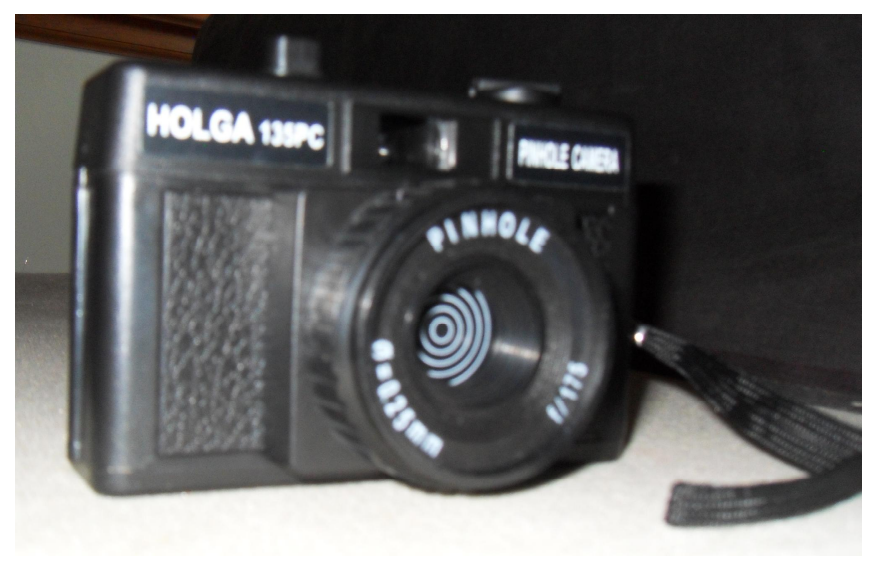

Figure 7 Holga 135 PC plastic pinhole camera

\subsection{Taking photographs}

The students were willing to try this photography even though taking photos on film seemed somewhat old fashioned and they would have to forgo instant results. One student commented, "I need to remember to advance the film." The students varied the exposure times on each photograph from 1 second to as much as 10 seconds. One group of students wanted to take photos of each other posing which required them to stand very still for the exposure time. As previously mentioned, this seldom produces a good portrait although in the hands of a skilled pinhole photographer it can result in some interesting "ghost" images. The other group of students used a variety of nature items with close-ups and distance shots. 


\subsection{Results}

In the end, the results from the Holga camera were a dismal failure. After taking four rolls of film to a large store to be developed and waiting for 4 weeks, the results were blank. At first evaluation, we thought the developers did not know how to develop film. Both cameras were tested prior to the workshop using black and white film under overcast weather conditions. A variety of outdoor photographs were taken with exposure times that varied from one second to six seconds. Though again the developing took several weeks, the results were good.

At this point, additional testing is required. Because the same developer was used for the test film and the workshop, it is uncertain whether it was a problem with the developing or with the technique of the students using the cameras or if it was a malfunction of the camera. We know that one camera was defective and the film would not advance.

The students were disappointed they waited so long for the results and had no photos to show. There are no results of student work to include in this paper.

\section{WORKSHOP 3: PROFESSIONAL PHOTOGRAPHY WORKSHOP}

\subsection{Robert Calafiore, professional photographer}

The third workshop of Pinhole Photography Day was presented by Robert Calafiore. As the professor and assistant dean of photography at the Hartford Art School at the University of Hartford, CT, Professor Calafiore provided demonstrations of the different cameras that he uses and the amazing results.

His collection, entitled "Revealed by Reflection" showcases very interesting and beautiful color photographs of pieces of glass arranged on mirrors, produced with a pinhole camera. The photos are an interesting combination of pinhole imaging, mirror reflection and artistic composition. He was able to share his pictures with the students and explained to them that pinhole photography is a unique method of taking pictures, with a camera that has no lens. The students were surprised at the time he takes to compose each photo, the long exposure times and the price he is able to command for each work of art.

In figure 8, Professor Calafiore is holding one of his large photography pieces. In front of him on the table are several of the cameras that he uses for taking these large scale photographs.

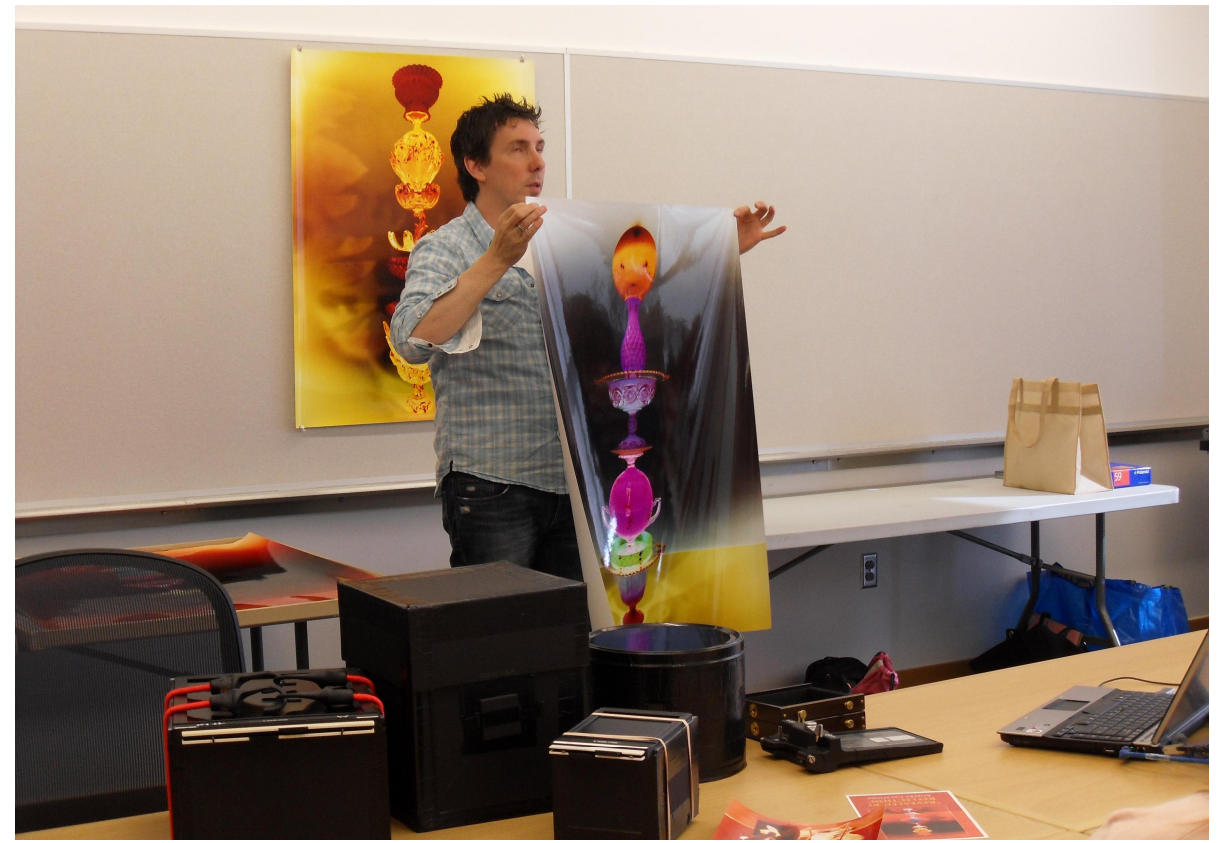

Figure 8 Robert Calafiore showing his pinhole photography. 
His lesson included the principles behind pinhole photography, explaining the relationship between his pinhole cameras and the camera obscura. Today, according to Professor Calafiore, pinhole photography is experiencing a rebirth and allowing artists to have a more 'hands on' approach to creating photographic images.

At the conclusion of this workshop, the students said that they were very impressed with both Professor Calafiore as well as his beautiful photographic works. They were surprised with the cost of the artwork and the amount of time that it takes to compose and shoot each work.

\section{CONCLUSION}

\subsection{Gallery walk}

At the conclusion of the three workshops, the three groups of students met for a "gallery walk." This was an opportunity for the students to share their results. Most students had the time to make two or three photos with their pinhole cameras. Some of the photos were very good but they were willing to share the photos that were not as good to use as learning examples (refer to figure 9)
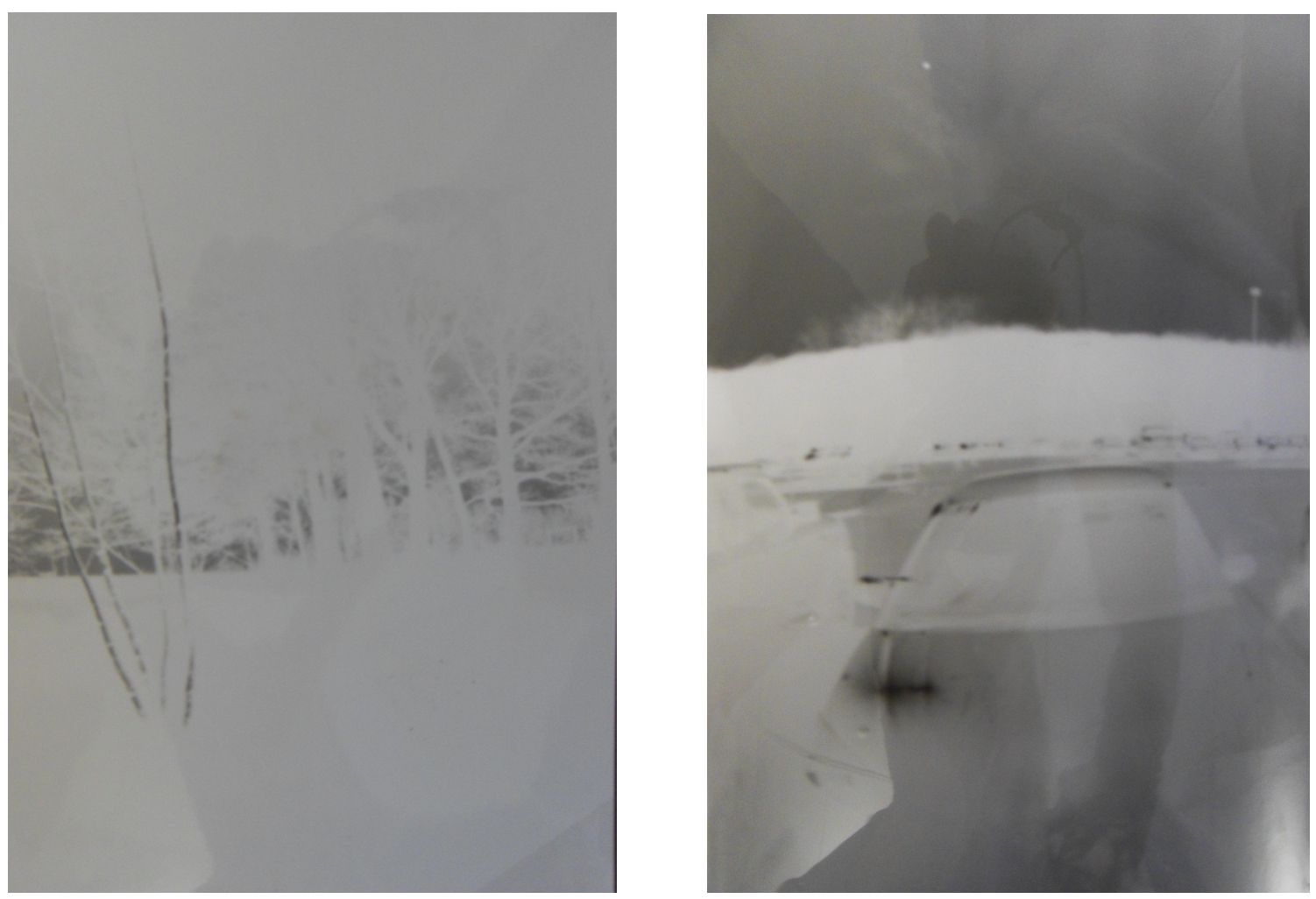

Figure 9 Student photos using oatmeal containers.

\subsection{Concluding student comments and success of Pinhole Camera Day}

As a result of this pinhole photography day, students discovered:

- "These pinholes actually take great pictures."

- "There is a great deal of math involved in this!"

- "Our eyes work like pinhole camera." 
- "I like comparing the pinhole camera pictures to the digital ones."

- "The pinholes are very interesting, I liked the black and while film."

In addition, it was a different application of math and science. The teachers appreciated the cross-curricular connections and that the students were engaged and interested in the workshops.

As is a feature of Laser Camp, the students enjoy making something and taking it back to show their fellow students and family. In this case, they each had several photos that they had not only taken with an oatmeal container pinhole camera but also developed themselves.

The success of Pinhole Photography Day in large part is due to the single theme of the day, reinforced through several workshops. Students remained focused on the activities and enjoyed and were somewhat surprised that the day combined science, technology, mathematics and art.

\section{ACKNOWLEDGMENTS}

Judy Donnelly, professor of Optics and Fiber Optic Technology at Three Rivers Community College (TRCC), Norwich, $\mathrm{CT}$

High school students from Lyman Memorial High School, Lebanon, CT and Windham High School, Willimantic, CT

Optical Society of America Foundation (OSAF) for funding supplies for the workshop.

Pinhole viewer and oatmeal container camera lessons were adapted from the PHOTON Projects of the New England Board of Higher Education, supported by the Advanced Technological Education Program of the National Science Foundation: PHOTON NSF/DUE \#0053284 and PHOTON2 NSF/DUE \#0302528.

Regional Center for Next Generation Manufacturing (RCNGM), supported by the Advanced Technological Education Program of the National Science Foundation NSF/DUE \#0903209 for additional funding of student workshops

Robert Calafiore, professor and assistant dean of photography at the Hartford Art School at the University of Hartford, CT.

SPIE outreach grant for funding supplies for the workshops.

\section{REFERENCES}

[1] J. Donnelly, D. Goyette, N. Magnani, K. Wosczyna-Birch. "Laser Camp: Shining a Light on Optics Careers", Proceedings of the SPIE Annual Meeting, San Diego, August, 2008.

[2] N. Magnani, J. Donnelly, "Optics in Eastern CT," be presented at the ETOP conference, Wales, U.K., July, 2009.

[3] S. L. Woodruff, "Oatmeal Box Pinhole Photography", http://users.rcn.com/stewoody/

[4] "How to Make and Use a Pinhole Camera", www.kodak.com/global/en/consumer/education/lessonPlans/pinholeCamera/pinholeCanBox.shtml

[5] Pinhole size calculation used the application at www.mrpinhole.com/holesize.php 